\title{
Regression, Progression and Renewal: The Continuous Redevelopment of Expertise in Police Use of Force Coaching
}

\author{
Mario S. Staller ${ }^{1} \mathbb{D} \cdot$ Swen Körner ${ }^{2}$
}

Received: 1 July 2020 / Accepted: 28 September 2020 / Published online: 16 October 2020

(c) The Author(s) 2020

\begin{abstract}
Professionalism in law enforcement requires the identification and development of expertise of police use of force (PUOF) coaches. Effective PUOF training includes the transfer from the training into the real-world environment of policing. This difference between working in the field and working as a PUOF coach has not been thoroughly investigated. However, research in other professional domains has shown that practical competence in the subject matter itself does not make a coach effective or successful. With this article, we conceptualize expert practice in PUOF instruction on the basis of a conflict management training setting in the security domain. First, by discussing a model of "territories of expertise", we point out the dynamic and contextual character of expertise within the PUOF domain. Second, by conceptualizing expertise as a process and effect of communication, we provide a framework that describes and examines the interdependency between performance-based and reputation-based expertise. These considerations present two practical challenges, which we recommend professional law enforcement institutions to engage. We close by providing practical orientations and pointers for addressing these issues.
\end{abstract}

Keywords Expertise $\cdot$ Police use of force training $\cdot$ Coaching $\cdot$ Professionality

\section{Introduction}

How can we develop expertise in teaching conflict management?

Mario S. Staller

mario.staller@hspv.nrw.de

Swen Körner

koerner@dshs-koeln.de

1 Department of Police, University of Applied Sciences of Police and Public Administration North Rhine-Westfalia, Aachen, Germany

2 Department of Training Pedagogy and Martial Research, German Sport University, Cologne, Germany 
Police use of force (PUOF) coaches and law enforcement decision-makers, who are responsible to prepare police officers for the conflict situations they face in the field, have asked this question all across Germany. Aware of the speculative nature of interpreting this question, we still perceive an insecurity concerning the developmental pathways of police use of force (PUOF) coaches and other security professionals. When we refer to PUOF coaches, we include "trainers", "instructors" in all disciplines related to enhancing the capacity of learners to deal with conflict in the field (e.g. firearms trainers, tactical instructors, selfdefence coaches, de-escalation coaches, etc.). In Germany, PUOF coaches are tasked to prepare officers for the demands of verbal or physical conflict situations that they may encounter during their operational duty in the field (Staller and Körner 2019). Depending on the organization and the federal state, PUOF coaches instruct recruits, regular duty officers or specialized personnel according to theirs specific needs. Correspondingly, internal and external factors and variables impact training in different ways (for instance, available training time and logistics but also PUOF coach qualifications). The transition from practitioner, like a regular duty police officer, to coach poses several unanswered questions (Staller 2019; Wood and Tong 2009). For example, Wood and Tong (2009) point out, that police trainers "have no recognised career pathway to follow as a trainer" (p. 302). While the authors address the transition from practitioner to teacher in general for law enforcement, research in the PUOF domain indicates that the difference between working in the field and working as a coach has not been thoroughly investigated yet (Staller and Zaiser 2015). Research in other professional domains, particularly in sport coaching, has shown that being a competent practitioner in the subject matter is not sufficient to be an effective and successful coach for that subject matter (Abraham and Collins 1998a, b; Sage 1989). In the context of PUOF research, recent evidence identified four issues, which may be the result of an undifferentiated perspective on the various contexts that underlie individual coaches' motivation to become an expert. These includes (a) a lack of awareness of the latest development in the training of PUOF, (b) a lack of pedagogical knowledge regarding the planning, delivery and reflection on training among PUOF coaches, (c) an unfocused view on what is needed to develop expertise in coaching, and (d) the biographical background of the coaches.

First, observational data from PUOF training in the UK (Cushion 2018) and Germany (Staller et al. a, b, c, d) suggest that PUOF coaches are not up-to-date concerning the latest developments in the training of physical conflict management. More specifically, coaches in the respective studies adhered to traditional models of teaching and instructing by "talking most of the time in order to share their accumulated wisdom, demonstrating simple or part drills (often without repetition), and giving some corrective information in de-briefs" (Cushion 2018, p. 6). It may be reasonable to assume that this pedagogical approach is based on the coaches' own experiences as learners in the respective settings (Hoy and Murphy 2001), instead of on critical reflection against current coaching knowledge (Staller et al. 2019b). This concerns the second aspect: the critical reflection on one's own coaching practice, requires underpinning knowledge that serves as a template (Abraham and Collins 1998a, 2011; Irwin et al. 2010). However, 
Staller and colleagues found in a recent study on 163 PUOF coaches (2020) that they appear to lack the declarative knowledge structures needed for reflection. Third, it seems that PUOF coaches (and decision-makers) are not fully aware of what is needed to develop coaching expertise. For example, PUOF coaches display a much stronger focus on developing expertise in the content they are teaching (i.e. conflict management) than to the competence of teaching itself (Staller et al. 2020). Also, concerning the subject matter of conflict management, PUOF coaches seem to have an unfocused view on what effective conflict management requires. While expert police practitioners are more aware of de-escalating behaviour and opportunities compared to novices (Mangels et al. 2020), PUOF coaches in Staller's et al. study (Staller et al. 2020) preferred the development of skill related coercion over that of de-escalative and communicating behaviour. The focus on specific content matter when planning one's own development in PUOF coaching, may also be a result of the fourth aspect: a more recent study on career pathways into PUOF training, Körner et al. (2019) provided evidence that PUOF coaches were either selected for this profession or chose this particular pathway based on their expertise and background in the specific subject matter, for instance martial arts, shooting or operational experience in special units.

These facets point towards the need to conceptualize expertise in PUOF coaching. In particular, the relationship between context and expertise may warrant further consideration. Expertise has to be demonstrated in a specific context (Billett 2001; Billett et al. 2018). Having a clear concept about what constitutes a context within the PUOF domain would enable PUOF coaches to progress towards expertise with focus and intent. Furthermore, delineating the relationship between performance-based expertise and reputation-based expertise (Gobet 2016) in the context of PUOF would contribute to the selection (e.g. background) and development of coaches within.

The purpose of this article is to contribute to the conceptualization of expert practice in PUOF coaching. In particular, the goal of the article is two-fold. First, we discuss the existing models of expertise related to the subject of conflict management and PUOF training. We focus on "territories of expertise" and how their dynamic nature provides the context, in which PUOF coaching expertise is displayed. Our intention is to acknowledge the dynamic and contextual nature of expertise within the PUOF and other security related domains. Second, by conceptualizing expertise as a process and effect of communication, we provide a framework for describing and examining the interdependency between performance-based and reputationbased expertise. This allows decision-makers to harness the benefits of this relationship while avoiding the corresponding pitfalls by adhering to professionals that have the reputation but not the skills.

In order to achieve these two goals, we start by providing an overview of the demands of expertise as it concerns conflict management and coaching within. Next, we discuss the models of expertise redevelopment (Grenier and Kehrhahn 2008) and renewal (Frie et al. 2018) with their applicability to PUOF training. Then, we turn to two practical challenges that we identified the need to be addressed by law enforcement institutions. We conclude by giving some practical orientations and pointers for addressing these issues. 


\section{The Demands of Expertise}

Over the course of the last decades, the demands of expertise has been investigated thoroughly by comparing the performance of experts with less-experienced practitioners or novices (Williams 2017). These investigations have usually been conducted within expertise domains, which are characterized by comparably stable and well-defined knowledge bases and by a domain-specific skill set, such as chess, mathematics and sports (Feltovich et al. 2018). In the context of PUOF, this approach has also been employed in order to investigate factors that comprise expertise within these settings (Boulton and Cole 2016; Mangels et al. 2020). For example, Boulton and Cole (2016) found that expert firearms officers are more flexible in adaptive responding to situational demands compared to their novice counterparts. Mangels et al. (2020) found that experts reported the importance of force mitigation opportunities more often after watching video footage from body-worn camera.

Concerning the sub-domain of physical conflict management, expert coaches of a reality-based self-defence system described rapid high-pressure decision-making skills as a key component in self-defence expertise (Staller et al. 2017; Staller and Abraham 2016). These results were also confirmed in a Delphi study (Staller et al. 2018), which investigated characteristics of expert performance in real life conflict situations. A panel of expert coaches of different backgrounds in terms of different self-defence systems and who all taught police forces agreed on various characteristics of expert performance. These characteristics included having a defensive mindset, focusing on de-escalating or avoiding physical conflict, being situational aware, act rapidly and decisively once a physical conflict hast started, and making use of situational parameters in order to gain a tactical advantage.

Even though these results provided some valuable insights into expert behaviour in (or in preparation for) conflict situations, they focus only narrowly on situations, where violence is in place or is about to happen. The interactional dynamics of police-citizen encounters in the development of the conflict (e.g. Klukkert et al. 2008; Todak and James 2018) and interventions that elicit conflict management expertise were not investigated. Yet, they seem to play a major role between expert and novice officers (Mangels et al. 2020).

While research aims at examining expert performance in conflict management (in a broad sense), it only constitutes the content a PUOF coach is conveying. The actual and crucial task of a coach is coaching. In carrying out this task, coaches make ongoing decisions that may be about macro strategic goals, meso planning goals, or micro moment to moment goals (Abraham and Collins 2011; Collins et al. 2014; Collins and Collins 2014). For example, PUOF coaches may have strategic goals of reducing the number of police injuries caused by physical engagements. To work towards this goal, they develop a long-term training plan to up-skill police officers in self-defence. At a day to day level these strategic and planning goals guide coaching tasks and interactions to create effective learning environments. Viewed in this way, coaching is a complex cognitive activity, which requires the capacity to solve numerous interconnected problems. Such a level of cognitive capacity is dependent on having sound knowledge across a number of domains (among them the content 
domain of physical and non-physical conflict management). Furthermore, it requires the capacity to employ that knowledge through judgement and decision-making to set and tackle these real-world problems by creating functional learning environments. This exemplifies that expertise in coaching is yet another domain in addition to expertise in conflict management in the field. For the context of coaching, Nash and Collins (2006) provided a summary of the key elements of expertise that have been identified through a range of different disciplines. These include

- Expertise is specific to domain and developed over a prolonged period of time;

- Experts recognize patterns faster than novices;

- Expert knowledge is structured to allow easier recall;

- Experts sort problems into categories according to features of their solutions;

- Experts initially are slower to solve problems than non-experts but are faster overall;

- Experts are more flexible and are more able to adapt to situations;

- Experts develop routines to allow processing capacity to be focused on ongoing environments; and

- Experts take deeper meanings from cues than novices.

While these characteristics provide a synoptic overview of the demands of expertise, Schempp et al. (2006) describe expert coaching in sports in more detail. According to their definition, expert coaches are outstanding performers in the coaching context and are "able to coach more athletes to higher levels of success in a greater variety of environments in a shorter amount of time than less expert coaches" (p. 155). They possess an extensive understanding about the subject matter they coach, the athletes they manage, and the skills and principles of coaching. They suggest that expert coaches are known to learn from a diverse variety of learning sources. However, despite possessing a comprehensive and detailed knowledge base, Schempp et al. (2006) point out that experts deliver information at a level that the recipient will understand. Furthermore, expert coaches often utilize intuition in their decision-making, underpinned by years of practical experience, and their extensive understanding of pertinent topics. Hence, expert coaches are said to decide intuitively and have the confidence to trust their intuition (Collins et al. 2016), even in situations where "those feelings run counter to accepted logic or convention" (Schempp et al. 2006, p. 157). Because of this, their actions and responses appear automated in nature, so that delivering training is performed with seemingly little effort but results in remarkable outcomes. However, despite years of experience, Schempp et al. (2006) point out that expert coaches invest high amounts of effort in preparation and planning. Expert coaches focus on attending to a typical situations by using their extensive knowledge base to make sense of any anomalies in order to select an action that will resolve the identified problem.

The descriptions of expertise in conflict management and coaching show that the specific domain of expertise is central in understanding how expertise develops, how it can be spotted, and how it is perceived by others (Farrington-Darby and Wilson 2006; Shanteau 1992). Individuals need learning opportunities in a specific domain to develop expertise and experts excel within their specific domain in comparison 
with other practitioners (Gobet 2016). However, in the context of PUOF training, two questions still have to be answered: What constitutes a specific domain, and how is the development of expertise influenced by the different domains and context? In order to answer these questions, we now focus on models of expertise (re) development.

\section{The $(\mathrm{Re})$ Development of Expertise}

Research on expertise development produced a number of different models that focus on how individuals proceed through different stages to become an expert in their domain (for a summary, see Ericsson 2014). For example, the model by Dreyfus and Dreyfus (1986) proposed a five-step model of skill development based on studies with fighter pilots and chess players. The model describes progressive stages from novice and advanced beginner, through competent performer and proficient performer, to expert. In the novice stage, a person follows rules that are contextfree and feels no responsibility for anything other than following the rules. Progression to advanced beginner occurs with significant practical experiences: the learner begins to perceive similarities of specific situations with prior examples of the same experience. Actions can now be based on both the new situation and the earlier context-free components. Competence develops after having a considerable amount of situational experience and context-free rules, which are put into a problem-solving formant by adopting a hierarchical decision-making process. Proficiency is shown in individuals who use intuition in decision-making and develop their own rules to formulate plans. Finally, the stadium of expertise is characterized by a fluid performance that happens unconsciously, automatically, and no longer depends on explicit knowledge. Progression according to this model is shown as a gradual transition from a rigid adherence to taught rules and procedures through to a largely intuitive mode of operation that relies heavily on deep, implicit knowledge. The Dreyfus model also accepts that sometimes experts are still likely to use analytical approaches when an intuitive approach fails initially. By passing through the different stages, distinct points of development are achieved. Yet, the model falls short on explaining in detail the process by which an individual moves from one stage to the other and what occurs after the expert-stadium has been achieved and expertise has been developed. The Dreyfus model is considered to be an influential example, as it represents staged models of expertise (e.g. Benner et al. 2009; Schempp et al. 2006; Tsui 2003). However, these models fall short on explaining how professional careers unfold, when expertise territories change and experts need to continuously renew their expertise in favour of the sustainability of their career. As such, the model is criticised in several professional domains, including coaching (Grenier and Kehrhahn 2008; Turner et al. 2012).

One major criticism of the staged models is that they do not reflect the realities of today's experts, who find themselves in in different situations and contexts in which their expertise must be adapted to fit new parameters, new scenarios, and new challenges (Grenier and Kehrhahn 2008). Grenier and Kehrhahn (2008) took an approach that accounts for the bounded field of expertise of an expert's work over 
the life span and which further specifies the influence of intentional and incidental changes to a domain on developing expertise. They proposed a model of expertise redevelopment that recognises expertise development as an infinite, cyclical, and fluid process founded on exploration, experimentation, and learning. According to this conceptualisation, full expertise is temporary at best and often considered unattainable (Nunn 2008). The model advocates for a major shift in the exploration of expertise by introducing the concept of "territories of expertise". The model "moves away from thinking of domain as merely a field of expert knowledge void of context and makes clear the complexity of influences and the overall context of one's expertise that can change an individual's existing knowledge, skills and knowing" (Grenier and Kehrhahn 2008, p. 206). These territories of expertise comprise three overlapping and interconnected contexts: constituency, content, and environment. Constituency refers to the various groups that influence or are influenced by the individual. For a PUOF coach, this might include interactions with the learning police officers, their supervisors, or the director of the training programme. Content encompasses the knowledge, skills, and specific information individuals need in order to function within their role. In the PUOF context, this may include the subject matter a PUOF coach uses. Compared to other models and theories of expertise, content is what corresponds best with what has been termed domain elsewhere (e.g. Dreyfus and Dreyfus 1986). Finally, the territorial context of environment refers to the locale an individual works in, including the culture, organisational structure, location, or specific layout. For example, a PUOF expert coach may be deemed an expert when conducting training sessions within a certain tactical training facility. He or she knows where learners are likely to experience difficulties in working through a scenario or where to get extra training equipment from for a more conducive tactical area. However, if the coach is reassigned to another tactical facility, the change in the environment may result in a need for new expertise. Even though constituency and content stay the same or similar, the change in environment necessitates a redevelopment of expertise. Taken together, the concept of territories of expertise posits that, when one or more of these factors (constituency, content, environment) are significantly altered, the individual is in need of redeveloping his/her expertise.

According to Grenier and Kehrhahn (2008), this redevelopment then takes place in three stages: (a) dependence, (b) independence, and (c) transcendence. In the first stage (dependence), experts need to rely on other individuals and resources, in order to learn to adapt his/her knowledge and skills to the new demands. For example, a PUOF coach who previously has taught recruits at the academy for several years is now assigned to teach regular officers to become PUOF coaches. In the stage of dependence, the PUOF coach has to rely on his colleagues and carefully listen to the learners, in order to learn about the needs of regular officers with many years of experience. The PUOF coach may understand that regular officers with many years of experience long for more de-escalation tactics and well-designed scenario trainings (Rajakaruna et al. 2017). Also, the motivation to engage in physically exhausting exercises may be different from those of recruits. During the second stage (independence), the expert becomes increasingly comfortable with the new information, skills and/or role, which allows him/her to add his/her existing knowledge base with new information. In our example, the PUOF coach now becomes confident in 
planning training sessions at an appropriate level of intensity for the officers. While before, the coach would have overestimated the physical capacity of regular officers, now, he/she aligns the level of intensity of the exercises with the actual capacity of the learners more easily. Also, the coach now knows what the assigned learners need. $\mathrm{He} / \mathrm{she}$ incorporates more scenarios that emphasize verbal and de-escalative solutions and allow for more variability among the avenues that lead to the successful resolution of the training scenarios. In the final stage (transcendence), the expert develops a sense of ownership and their expertise becomes more tacit. Grenier and Kerhahn (2008) conclude that in this stage "individuals are secure in their knowledge and abilities to such an extent that they are free to improvise and to feel confident in challenging and altering existing practices" (p. 11). Hence, experts amend their existing repertoire by research and experimentation. The expert now easily switches "on-the-spot", when learning opportunities occur (Körner and Staller 2019; Schön 1983). He/she easily picks up cues about fatigue in the training session and adapts the level of intensity of exercises that are appropriate for some learners, while he/she adapts the session for others. Even though there are three different stages, the model of expertise redevelopment differs from the staged models of expertise. It recognizes the contextual factors that may influence a practitioner's level of expertise, which could result in regression and progression by starting a cycle of re-development of expertise.

The use of the model of expertise redevelopment for understanding expertise in sport coaching has been acknowledged by Turner et al. (2012). The authors provide a lively, practical example within their article and demonstrate the applicability of the model in the domain of coaching. The emphasis on territories of expertise and its influence on regression and progression of skill provides a valuable framework for tackling practical challenges that exist within martial settings. However, the model of expertise redevelopment provides no explanation of how experts (re) develop their expertise in interaction with elements of their environment. It also falls short in addressing how individual expertise adapts to different audiences and at multiple levels of an organization.

This question has recently been addressed in an interview study with ten high level experts, who are regularly developing and defining new areas of expertise (Frie et al. 2018). Based on their results, the authors developed a model of expertise renewal. They describe renewal episodes of experts (the authors speak of "flexperts") that consist of several phases, which experts move back and forth between: (a) exploring new expertise domains, (b) creating simulating context, and (c) materializing ideas and new expertise. In the first phase, experts explore the new expertise domain by testing generated ideas about the new, adjacent domain of expertise. Furthermore, they acquire new knowledge and skills to enrich their generated ideas by weighing "both the potential of having beneficial outcomes for themselves as well as for relevant stakeholders" (Frie et al. 2018, p 13). For instance, a wellrespected PUOF coach identifies, based on current evidence (Rajakaruna et al. 2017; Staller et al. 2019a, b, c, d; Wolfe et al. 2020), a lack of training in de-escalating tactics within PUOF training of his/her service. By participating in courses (e.g. deescalation courses, crisis communication, etc.) and self-study, our coach acquires the content knowledge needed to advance training in the department. Next, experts 
start several processes that help them creating a stimulating context in three different ways. First, they claim new expertise, once they have sufficient knowledge or skill acquired, which helps them to build up an expert reputation. Second, they create networks of ambassadors, who help them with further testing and providing additional knowledge and skills. Finally, this can help to create space, which Frie et al. (2018) describe as "the possibility to circumvent processes, gaining access to financial resources, having time available, and taking distance for further exploration (p. 13). In our example, the PUOF coach designs a weekly "communication session", where officers have to solve scenarios with verbal and non-verbal communication only. By advertising these sessions throughout the department and providing lectures about the topic, the PUOF coach gains a reputation as a de-escalation expert. Learners, that have visited the training session are fascinated from this new approach in the department. As such, they advertise the sessions among their peers. Through the initial performance and the now built-up reputation, the coach is assigned to more de-escalation sessions and is confronted with the task to increasingly incorporate communicative behaviour in the regular PUOF training. This brings us to the last phase in the model of expertise renewal. The phase of materializing ideas and new expertise usually starts after a number of exploration cycles. Frie et al. (2018) state that this "is the stage in which it usually becomes clearer as to how a tested idea, enriched with new knowledge and skills, can be materialized after also having been able to create a (more) stimulating context. This materialization is realized by the development of tangible products for multiple stakeholders inside and outside an organization. It often requires the fine-tuning of products for which experts involve other experts among their network of ambassadors who have complementary or indepth expertise on components of the desired output" (p. 13).

In our example, the coach has now multiple opportunities to fine-tune the new product. Since fellow police officers report back from the field, when something has worked and when something did not, the coach can adapt the training sessions accordingly. He or she now builds up a repertoire of different scenarios, which can be used throughout the PUOF training sessions. This manifests the his/her reputation as a PUOF coach, who can teach how to cope with all facets of conflict.

According to Frie et al. (2018), each renewal episode has some personal outcomes that support the experts in the subsequent episodes throughout their career: First, the exploration cycle produces new ideas and knowledge, which, in turn, has a positive impact on the expert's reputation and the generation of new ideas. Second, the positive reputation enhances other people's willingness to become the expert's ambassadors enhancing the expert's social network. Third, this network then helps during future renewal episodes by providing expertise and resources, which help the exploration and materialization of knowledge and skills. Fourth, having space also helps in creating room to focus on a subsequent renewal episode. And finally, the materialization of the expert's knowledge and skills ultimately leads to a positive expert performance evaluation, which is in line with the individual's personal mission. For our coach, the personal mission may be to contribute to the optimization of PUOF training. By adding the aspect of communication successfully in the current PUOF practice within the department, our coach has earned the reputation of someone, who is able to design new training concepts for the demands in the field. In our 
example, the department has an increasing number of incidents involving individuals that are mentally ill. Consequently, our coach is tasked (or initiates) a revision of the current curriculum concerning the interaction with individual in crisis. Since the reputation of our coach precedes his performance, our coach will be provided with all required resources. Finally, this starts starting a personal episode of expertise renewal again.

Based on the considerations laid out above, our review of the two conceptualisations of expertise and its applicability in the PUOF domain provides valuable insight into coaching in PUOF. In particular, (a) the concept of territories of expertise and (b) the contextual factors, specifically the communication about expertise and its impact within the organization, pose PUOF coaches and decision-makers within police institutions with two practical challenges.

\section{Practical Challenge 1: Mapping the Domains and Territories of Expertise}

The first practical challenge police institutions have to face concerns the domain and the territories of expertise of PUOF coaches. It is related to the actual performance of (to be developed) expert coaches. Since expertise is domain-specific (Gobet 2016) and working as a coach continuously involves adapting to new contextual factors (Turner et al. 2012), the territories of a coach's expertise have to be aligned with the territories a coach works in. Also, from a human resource development perspective, coaches need the resources and the motivation allowing them to adapt to new territories. On a general level, this involves a clear differentiation between different territories, especially in terms of (a) coaching and performance in the field that is coached (e.g. regular officers, tactical units, etc.), (b) the (performance) domains of conflict management (e.g. communication, de-escalation, physical coercion, firearms, etc.), (c) the learning officers who are trained and (d) the specific environment with the particular resources the PUOF coach is working in.

Regarding the first aspect, coaching and performance in the field that is coached, it seems obvious that these domains are related, yet very different. Concerning the development pathways of coaches in PUOF, research indicates that coaches frequently have an explicit background in combative disciplines like martial arts or self-defence systems, firearms related activates, and/or as practitioners in the special operational environment (Körner et al. 2019). While having a deep understanding of the conflict management is essential for coaching in that domain, good coaching does not necessarily result from a deep understanding of conflict management. Coaching, as indicated before, also involves knowledge from other domains, which has to be integrated in the coaches' processes of planning and providing decisions (Abraham and Collins 2011). A recent study on the topics, sources, and application of PUOF coaching knowledge (Staller et al. 2020) indicated that PUOF coaches focus more on content specific knowledge than other areas related to coaching (e.g. pedagogy). Another related aspect is the fact that performers need to work out what works for them, whereas coaches have to focus on what works specifically for each individual learner or groups of learners. This concerns learning pathways (Pesce 
et al. 2016) as well as specific solutions to specific problems in the field (e.g. techniques; see Körner and Staller 2018, for a summary on this issue). Professional development initiatives should be aware of the difference between performance in the field and coaching, in order to develop what is needed for coaching itself. On a positive note, this will allow practitioners to pursue another career development path. On the flip side, it may contradict what PUOF coaches actually want and are motivated to learn. This issue is also addressed by the second aspect: the domains of conflict management. The motivation to engage in a subject matter related to conflict management in coaching often seems to stem from an individual's own background in this content (Körner et al. 2019). This presents a challenge to the extent that conflict management in policing encompasses a variety of different options, which range from communicative and de-escalative non-physical tactics, to physical tactics, such as the use of physical force, arrest techniques, tactical behaviour, or the use of firearms. There is no doubt that coping with conflict is a highly dynamic, complex, and interactive process between all parties involved (Staller and Körner 2020; Todak and James 2018) that asks for an integrated skill set of professionals coping with such situations. The adherence to a narrow-focused territory within the landscape of conflict management may negatively influence the awareness of other options of conflict management and more appropriate solutions. This has been indicated by several studies, were learners suggest that a more comprehensive skill set is needed for coping with conflict in the field (Rajakaruna et al. 2017; Staller et al. 2019a). As such, institutions may consider (a) having a diverse PUOF coach team that reflects all specific areas of conflict management, and (b) ultimately develop their coaches in the direction of holistic conflict management. Concerning the third aspect, the learning officers that are trained, expertise has to be (re)developed according to the officers that are trained. While, for example, a coach for special units, has primarily to focus on coercive means (e.g. tactical behaviour of highly trained teams, firearms skills, etc.), a PUOF coach for regular officers may have to apply a more comprehensive focus on conflict management, at the expense of use of force options of highly specialized units. Finally, when mapping specific territories, the specific environment the PUOF coach works in has to be considered. Depending on the department, location, and the associated resources a PUOF coach can draw upon, coaching has to be adapted accordingly. While some departments may have the resources to design scenario trainings on a high level of physical representativeness and with a low coach to learner ratio, other coaches have to conduct training under more environmental constraints.

On the bottom line, these aspects should raise awareness about the developmental pathways of PUOF coaches as the selection of PUOF coaches. While expertise can be developed depending on the territory that a coach is supposed to work in, the motivation to do so is crucial. On an organizational level, selection processes may want to consider this. 


\section{Practical Challenge 2: Performance-Based Expertise versus Reputation-Based Expertise}

The review of research regarding the nature of expertise mainly emphasized the performance aspect within a specific domain. However, expertise also encompasses a social dimension. That is an expert excels in comparison with other practitioners. This is regularly reflected in definitions of experts (see Farrington-Darby and Wilson 2006, for a review). This comparison is implicitly conveyed, when somebody talks about "an expert". However, it is the exception that performance measures or ratings are readily available in the PUOF domain. Yet, expertise is assumed at some point, often based on the years that an individual has engaged in a specific activity. This problem has also been identified, when conducting research with "experts". The criteria that define somebody as an expert sometimes seem arbitrary. For example, in combat sport experts are labelled as the ones having had more than 8 to 10 years of experience (Fontani et al. 2007; Piras et al. 2014), whereas others defined athletes who had 4-6 years of experience as experts (Mori et al. 2002). Likewise, Preddy et al. (2019) defined expert PUOF coaches as individuals with a minimum of 8 years as police officers and minimum of 2 years coaching experience, whereas Mangels et al. (2020) identified expert practitioners (not coaches) by their departments' commanders: "experienced officers who were qualified as use-of-force instructors and police academy instructors" (p. 3). These examples show the overlap between performance-based expertise (and the challenge concerning territories of expertise) and reputation-based expertise. When performance is hard to assess objectively, expertise is judged by others. Therefore, it appears as an effect of communication.

In PUOF coaching, this becomes a problem, when future personal is recruited based solely on reputation that may not necessarily be related to performance. Data from the developmental pathways of German PUOF coaches (Körner et al. 2019) shows that the reputation of being a competent martial artist may sometimes be sufficient to be recruited as a PUOF coach. This aspect also concerns the different territories of expertise (practitioner vs. coach): a PUOF expert might build a reputation based solely on the time he/she works as a PUOF coach, without necessarily acquiring the skills backing up this expertise. In order to develop PUOF coaches under an expertise-framed approach, experience is a necessary, but not a sufficient condition (Collins et al. 2014). It requires experimentation and purposeful reflections on experiences in order to develop the adaptability, judgement, and decision-making that is needed for professional coaching (Abraham and Collins 2011; Collins et al. 2014; Collins and Collins 2014; Staller and Zaiser 2015). However, from an optimistic perspective, developmental pathways of PUOF coaches may also take another turn. Frie et al. (2018) identified the materialization of expertise based on reputation, which facilitates the provision of resources, especially opportunities (e.g. stimulating contexts). This in turn develop and manifest one's expertise in a specific context even further. Expertise as a construct of communication goes both ways: it enables reputation, which, in turn, enables opportunities for actually gain the knowledge and skills needed for expert performance. For instance, the combat sport athlete, who 
becomes a PUOF coach (because of his reputation) develops the skills and knowledge that ultimately qualify him as an actual expert.

In order to address the problem of actual performance-based expertise versus reputation-based expertise, institutions might adhere to consented classification of expert PUOF coaches. For example, criteria for the classification of expert coaches have been recommended before (Nash et al. 2012) and used in studies with samples of expert coaches in the domain of conflict management (Staller et al. 2018). According to these criteria, an expert coach applies a large declarative knowledge base to problem-solving and decision-making, and utilizes perceptual skills, mental models, sense of typicality, and associations, as well as routines. Furthermore, the expert coach demonstrates the ability to work independently and is capable of producing novel and innovative solutions. He/she demonstrates effective reflection skills and lifelong learning attitude to his/her development. The expert coach also takes his/her own strengths and limitations into account. Finally, he/she manages complex training processes. When taking these criteria into account, decision-makers can capitalize on the benefits of the relationship between performance-based and reputation-based expertise. At the same time, they can avoid the corresponding pitfalls by adhering to professionals who have a reputation but not the skills. As such, the selection and development processes of future PUOF expert coaches may focus on the criteria by Nash and colleagues (2012).

\section{Conclusion}

In order to further professionalize PUOF coaches both on a developmental and organizational level, key differences in expertise have to be taken into account. First, expert practice in the subject matter does not automatically warrant for expertise in effective coaching within that subject matter. Second, according to latest research, expertise in PUOF coaching is conceptualized as dynamic, adaptive, context-related, and recursive in nature, rather than the single dimension of an entity or the achievement of a final state of competence. Furthermore, the role of communication for the (re)development of domain-specific expertise is a key factor for an appropriate understanding of the intertwined relationship between performance-based and reputation-based expertise. By conceptualizing expertise as process and effect of communication, law enforcement institutions are challenged to create informed standards regarding substantial criteria, functional tools, and resources required for the mapping and development of expertise in PUOF coaching. With this article, we provide orientations to this.

Acknowledgements We thank Benni Zaiser for his valuable support concerning the current manuscript. We thank the anonymous reviewers for their suggestions and comments improving our manuscript.

Funding Open Access funding enabled and organized by Projekt DEAL.

Open Access This article is licensed under a Creative Commons Attribution 4.0 International License, which permits use, sharing, adaptation, distribution and reproduction in any medium or format, as long as you give appropriate credit to the original author(s) and the source, provide a link to the Creative 
Commons licence, and indicate if changes were made. The images or other third party material in this article are included in the article's Creative Commons licence, unless indicated otherwise in a credit line to the material. If material is not included in the article's Creative Commons licence and your intended use is not permitted by statutory regulation or exceeds the permitted use, you will need to obtain permission directly from the copyright holder. To view a copy of this licence, visit http://creativecommons.org/ licenses/by/4.0/.

\section{References}

Abraham A, Collins DJ (1998a) Declarative and procedural knowledge assessment in novice and intermediate coaches. J Sports Sci 16(1):70. https://doi.org/10.1080/026404198366966

Abraham A, Collins DJ (1998b) Examining and extending research in coach development. Quest 50(1):59-79

Abraham A, Collins DJ (2011) Effective skill development: how should athletes' skills be developed? In: Button A, Richards H (eds) Performance psychology: a practitioners guide. Churchill Livingstone, London, pp 207-229. https://doi.org/10.1016/b978-0-443-06734-1.00015-8

Benner P, Tanner C, Chesla C (2009) Expertise in nursing practice: caring, clinical judgment, and ethics. Springer, New York

Billett S (2001) Knowing in practice: re-conceptualising vocational expertise. Learn Instr 11(6):431-452

Billett S, Harteis C, Gruber H (2018) Developing occupational expertise through everyday work activities and interactions. In: Ericcson KA, Hoffman RR, Kozbalt A, Williams AM (eds) The Cambridge handbook of expertise and expert performance, 2nd edn. Cambridge University Press, Cambridge, pp 105-126

Boulton L, Cole JC (2016) Adaptive flexibility examining the role of expertise in the decision making of authorized firearms officers during armed confrontation. J Cogn Eng Dec Mak 10(3):291-308. https ://doi.org/10.1177/1555343416646684

Collins L, Collins DJ (2014) Integration of professional judgement and decision-making in high-level adventure sports coaching practice. J Sports Sci 33(6):622-633. https://doi.org/10.1080/02640 414.2014.953980

Collins D, Burke V, Martindale A, Cruickshank A (2014) The illusion of competency versus the desirability of expertise: seeking a common standard for support professions in sport. Sports Med 45(1):1-7. https://doi.org/10.1007/s40279-014-0251-1

Collins DJ, Collins L, Carson HJ (2016) "If it feels right, do it": intuitive decision making in a sample of high-level sport coaches. Front Psychol 7(1083):366-410. https://doi.org/10.3389/fpsyg.2016.00504

Cushion CJ (2018) Exploring the delivery of officer safety training: a case study. Policing 5(4):1-15. https://doi.org/10.1093/police/pax095

Dreyfus HL, Dreyfus SE (1986) Mind oder machine: the power of human intuition and expertis in the era of the computer. The Free Press

Ericsson KA (2014) Adaptive expertise and cognitive readiness: a perspective from the expert-performance approach. In: ONeil H, Perez RS, Baker EL (eds) Teaching and measuring cognitive readiness. Springer, Boston, MA pp 179-197. https://doi.org/10.1007/978-1-4614-7579-8_10

Farrington-Darby T, Wilson JR (2006) The nature of expertise: a review. Appl Ergon 37(1):17-32. https ://doi.org/10.1016/j.apergo.2005.09.001

Feltovich PJ, Prietula MJ, Ericsson KA (2018) Studies of expertise from psychological perspectives: historical foundations and recurrent themes. In: Ericsson KA, Hoffman RR, Kozbelt A, Williams AM (eds) The Cambridge handbook of expertise and expert performance, 2nd edn. Cambridge University Press, Cambridge, pp 59-83

Fontani G, Lodi L, Felici A, Migliorini S, Carradeschi F (2007) Attention in athletes of high and low experience engaged in different open skill sports. Percept Mot Skills 102(3):791-805

Frie LS, Potting KCJM, Sjoer E, der Heijden BIJMV, Korzilius HPLM (2018) How flexperts deal with changing expertise demands: a qualitative study into the processes of expertise renewal. Hum Resour Dev Q 30(1):61-79. https://doi.org/10.1002/hrdq.21335

Gobet F (2016) Understanding expertise: a mulit-disciplinary aproach. Palgrave, London 
Grenier RS, Kehrhahn M (2008) Toward an integrated model of expertise redevelopment and its implications for HRD. Hum Resour Dev Rev 7(2):198-217. https://doi.org/10.1177/1534484308316653

Hoy AW, Murphy PK (2001) Teaching educational psychology to the implicit mind. In: Torff B, Sternberg RJ (eds) Sport coaching: professionalisation and practice. Lawrence Erlbaum, Mahwah, pp $145-184$

Irwin G, Hanton S, Kerwin D (2010) Reflective practice and the origins of elite coaching knowledge. Reflect Pract 5(3):425-442. https://doi.org/10.1080/1462394042000270718

Klukkert A, Ohlemacher T, Feltes T (2008) Torn between two targets: German police officers talk about the use of force. Crime Law Soc Change 52(2):181-206. https://doi.org/10.1007/s10611-008-9178-5

Körner S, Staller MS (2018) From system to pedagogy: towards a nonlinear pedagogy of self-defense training in the police and the civilian domain. Secur J 31(2):645-659. https://doi.org/10.1057/s4128 4-017-0122-1

Körner S, Staller MS (2019) Situativität im Coaching [Situativeness in coaching]. In: Meyer M, Staller MS (eds) "Lehren ist Lernen: Methoden, Inhalte und Rollenmodelle in der Didaktik des Kämpfens" : internationales Symposium; 8. Jahrestagung der dvs Kommission "Kampfkunst und Kampfsport" vom 3.-5. Oktober 2019 an der Universität Vechta; Abstractband. Deutsche Vereinigung für Sportwissenschaften (dvs), p 43

Körner S, Staller MS, Kecke A (2019) „Weil mein Background da war...“-Biographische Effekte bei Einsatztrainern*innen ["Because my background was...-Biographical effects for police trainers]. In: Meyer M, Staller MS (eds), "Lehren ist Lernen: Methoden, Inhalte und Rollenmodelle in der Didaktik des Kämpfens" : internationales Symposium; 8. Jahrestagung der dvs Kommission "Kampfkunst und Kampfsport" vom 3.-5. Oktober 2019 an der Universität Vechta; Abstractband. Deutsche Vereinigung für Sportwissenschaften (dvs), pp 17-18

Mangels L, Suss J, Lande B (2020) Police expertise and use of force: using a mixed-methods approach to model expert and novice use-of-force decision-making. J Police Crim Psychol 85(6):1-10. https://doi.org/10.1007/s11896-020-09364-4

Mori S, Ohtani Y, Imanaka K (2002) Reaction times and anticipatory skills of karate athletes. Hum Mov Sci 21(2):213-230

Nash CS, Collins DJ (2006) Tacit knowledge in expert coaching: science or art? Quest 58(4):465-477. https://doi.org/10.1080/00336297.2006.10491894

Nash CS, Martindale R, Collins DJ, Martindale A (2012) Parameterising expertise in coaching: past, present and future. J Sports Sci 30(10):985-994. https://doi.org/10.1080/02640414.2012.682079

Nunn R (2008) A network model of expertise. Bull Sci Technol Soc 28(5):414-427. https://doi. org/10.1177/0270467608322587

Pesce C, Croce R, Ben-Soussan TD, Vazou S, McCullick B, Tomporowski PD, Horvat M (2016) Variability of practice as an interface between motor and cognitive development. Int J Sport Exerc Psychol 17(2):133-152. https://doi.org/10.1080/1612197x.2016.1223421

Piras A, Pierantozzi E, Squatrito S (2014) Visual search strategy in judo fighters during the execution of the first grip. Int J Sports Sci Coach 9(1):185-197

Preddy JE, Stefaniak JE, Katsioloudis P (2019) The convergence of psychological conditioning and cognitive readiness to inform training strategies addressing violent police-public encounters. Perform Improv Q 5(4):1-32. https://doi.org/10.1002/piq.21300

Rajakaruna N, Henry PJ, Cutler A, Fairman G (2017) Ensuring the validity of police use of force training. Police Pract Res 18(5):507-521. https://doi.org/10.1080/15614263.2016.1268959

Sage GH (1989) Becoming a high school coach: from playing sports to coaching. Res Q Exerc Sport 60(1):81-92. https://doi.org/10.1080/02701367.1989.10607417

Schempp PG, McCullick B, Mason IS (2006) The development of expert coaching. In: Jones R (ed) The sports coach as educator: re-conceptualising sports coaching. Routledge, London, pp $145-161$

Schön DA (1983) The reflective practitioner: how professionals think in action. Basic Books, New York

Shanteau J (1992) Competence in experts: the role of task characeristics. Organ Behav Hum Decis Process 53:252-266

Staller MS (2019) The journey is the destination: an expertise-oriented perspective on thinking, experiencing and practicing martial arts, combat sports and self-defence. In: Niehaus A (ed) Abstracts of the 7th annual conference of the committee for martial arts studies in the German association of sport "experiencing, training and thinking the body in martial arts and martial sports", November 15-17, 2018, Ghent, Belgium, p 4. Journal of Martial Arts Research, 2(2) 
Staller MS, Abraham A (2016) "Work on your problem-solving": krav maga experts' views on optimal learning environments for self-defence training. Int J Coach Sci 10(2):91-113

Staller MS, Körner S (2019) Quo vadis Einsatztraining? [Quo vadis police training?]. In: Kühne E (ed) Die Zukunft der Polizeiarbeit—die Polizeiarbeit der Zukunft-Teil II. Eigenverlag der Hochschule der Sächsischen Polizei (FH), pp 321-364

Staller MS, Körner S (2020) Komplexe Gewaltprävention: Zum Umgang mit Gewalt auf individueller Ebene [Complex Violence Prevention: Coping with Violence on an Individual Level]. Österreichische Zeitschrift Für Soziologie 45(Suppl 1):157-174. https://doi.org/10.1007/s11614-02000413-0

Staller MS, Zaiser B (2015) Auf dem Weg zur Expertise als Einsatztrainer: Selbst-bestimmtes Lernen im Rahmen der regelmäßigen Dienstverrichtung [On the way to expertise as a police use of force trainer: self-directed learning in the context of daily routine]. Poliz Wiss 4:39-49

Staller MS, Abraham A, Poolton JM, Körner S (2017) It's not about the pain-it's about the feedback': krav maga experts' views on self-defence performance and the experience of contact, pain and injury in the process of skill development. Arch Budo 13:35-49

Staller MS, Abraham A, Poolton JM, Körner S (2018) Avoidance, deescalation and attacking: an expert coach consensus in self-defence practice. Mov J Phys Educ Sport Sci 11(3):213-214

Staller MS, Körner S, Heil V, Kecke A (2019a) „Draußen ist es nie so wie es hier ist“-Die Wahrnehmung von Einsatz- und Konfliktsituationen von Polizeikommissarsanwärter*innen. In: Niehaus A (ed) Abstracts of the 7th annual conference of the committee for martial arts studies in the german association of sport "experiencing, training and thinking the body in martial arts and martial sports", November 15-17, 2018, Ghent, Belgium, p 33. Journal of Martial Arts Research, 2(2)

Staller MS, Körner S, Heil V, Kecke A (2019b) Mehr gelernt als geplant? Versteckte Lehrpläne im Einsatztraining [More learned than planed? The hidden curriculum in police use of force training]. In: Frevel B, Schmidt P (eds) Empirische Polizeiforschung XXII Demokratie und MenschenrechteHerausforderungen für und an die polizeiliche Bildungsarbeit. Verlag für Polizeiwissenschaft, pp $132-149$

Staller MS, Körner S, Heil V, Klemmer I, Kecke A (2019c) Die Trainingspraxis im polizeilichen Einsatztraining: Eine Fallstudie. In: Niehaus A (ed) Abstracts of the 7th annual conference of the committee for martial arts studies in the German association of sport "experiencing, training and thinking the body in martial arts and martial sports", November 15-17, 2018, Ghent, Belgium. Journal of Martial Arts Research, 2(2)

Staller MS, Körner S, Heil V, Klemmer I, Kecke A (2019d) „War ne Runde Sache“—Die reflexive Coaching Praxis von polizeilichen Einsatztrainer*innen [,,It was a round thing”-The reflective coaching practice of police trainers]. In: Meyer M, Staller MS (eds) "Lehren ist Lernen: Methoden, Inhalte und Rollenmodelle in der Didaktik des Kämpfens": internationales Symposium; 8. Jahrestagung der dvs Kommission "Kampfkunst und Kampfsport" vom 3.-5. Oktober 2019 an der Universität Vechta; Abstractband. Deutsche Vereinigung für Sportwissenschaft (dvs), pp 15-16

Staller MS, Körner S, Abraham A, Poolton J (2020) Topics, sources and the application of coaching knowledge in police training (Manuscript in Preparation)

Todak N, James L (2018) A systematic social observation study of police de-escalation tactics. Police Q 18(2):109861111878400. https://doi.org/10.1177/1098611118784007

Tsui ABM (2003) Understanding expertise in teaching. Cambridge University Press, Cambridge

Turner D, Nelson L, Potrac P (2012) The journey Is the destination: reconsidering the expert sports coach. Quest 64(4):313-325. https://doi.org/10.1080/00336297.2012.706886

Williams AM (2017) Using the 'Expert Performance Approach'as a framework for examining and enhancing skill learning: improving understanding of how experts learn. Frontl Learn Res. https:// doi.org/10.14786/flr.v5i3.267

Wolfe S, Rojek J, McLean K, Alpert G (2020) Social interaction training to reduce police use of force. Ann Am Acad Polit Soc Sci 687(1):124-145. https://doi.org/10.1177/0002716219887366

Wood DA, Tong S (2009) The future of initial police training: a university perspective. Int J Police Sci Manag 11(3):294-305. https://doi.org/10.1350/ijps.2009.11.3.131

Publisher's Note Springer Nature remains neutral with regard to jurisdictional claims in published maps and institutional affiliations. 